\title{
Assessing Disclosure Quality: A Methodological Issue
}

\author{
Davide Scaltrito \\ University of Turin, Torino, Italy
}

\begin{abstract}
The voluntary disclosure studies conducted until today, in social accounting and related fields, use different approaches to evaluate the so-called "disclosure quality”. Disclosure quality is not so easy to measure, and it is derived from the application of different methodologies. In particular, the methodologies to assess the level of disclosure could be classified as subjective or objective. To the first category belong all the "tools" that are used directly without relying on the analysis of the original source of the information studies (Imhoff, 1992; Coleman \& Eccles, 1997; Welker, 1995). The objective measurements used to assess the disclosure quality are, instead, based on the direct study of the original information source in order to obtain the information required (Krippendorff, 1980; Weber, 1985; Botosan, 1997; Lang \& Lundholm, 2000). The aim of the paper is to give scholars and researchers a brief framework to understand the different methodologies used in accounting literature to assess the disclosure quality, providing examples of the application of the same in different research contexts.

Keywords: voluntary disclosure quality, disclosure studies methodologies, disclosure index, disclosure measurements tools
\end{abstract}

\section{Introduction}

The disclosure of voluntary information is a "spotlight" topic for accounting researchers and scholars. Voluntary disclosure refers to the discretionary release of financial and non-financial information which companies are not obliged to disclose by a standard-setting accounting body. The provision of additional information, not specifically required by laws, is becoming increasingly important in order to make a firm more competitive. This guarantees transparency for stakeholders. Meek, Roberts, and Gray (1995, p. 555) defined voluntary disclosure as "free choices on the part of company managements to provide accounting and other information deemed relevant to the decision needs of users of their annual reports”. The need to voluntarily disclose information is explored by accounting literature through different theories. As scholars argued, disclosure is a complex phenomenon that cannot be explained by only one theory (Adrem, 1999; Cormier, Magnan, \& Van Velthoven, 2005). One of the main problems is how to assess the so-called disclosure quality. The term "disclosure quality" is used in accounting literature as being synonymous for the "level of information disclosed by firms"; but how can we measure in quantitative terms a phenomenon such as disclosure of information? (It seems to be more a qualitative concept probably). In international accounting literature, all the studies that focused on the disclosure of voluntary or mandatory information used different approaches in order to measure disclosure quality. In particular, in order to assess the level of disclosure provided by firms in different studies, the following tools were used:

Davide Scaltrito, Ph.D., Department of Management, University of Turin. Email: davide.scaltrito@unito.it. 
(1) Subjective tools (i.e., survey, questionnaire, external rating, and analyst opinion); all the "tools" that are used directly without relying on the analysis of the original source of the information studies (Imhoff, 1992; Coleman \& Eccles, 1997; Welker, 1995);

(2) Objective tools (i.e., content analysis, disclosure index, event frequencies); these categories of tools are based on the direct study of the original information source (Krippendorff, 1980; Weber, 1985; Botosan, 1997; Lang \& Lundholm, 2000).

\section{Subjective Instruments for Measuring the Level of Disclosure}

The main tool used, classified among those that form part of a subjective approach in the assessment of the quality of disclosure, is that of interviews and questionnaires which are also referred to as a "survey" or "investigation" by some authors (Hassan \& Marston, 2010) which aims to provide a rating to the researcher or those wishing to understand the level of disclosure of certain companies.

The use of questionnaires and interviews requires the inherent perception of certain categories of users (such as investors, analysts) on the company's disclosure practices which in turn will provide reports containing certain evaluations.

In USA, many studies on financial disclosure are based on the above. In particular, many surveys are carried out by two main bodies: the Financial Analyst Federation (FAF) and the Institute of Chartered Financial Analyst (ICFA) which merged to form the Association for Investment Management and Research (AIMR), and then from 2004 was renamed as the Chartered Financial Analyst (CFA).

The abovementioned entities provide reports containing an overall assessment or evaluation carried out on the disclosure practices of large companies from different sectors. Typically, an average of 20 sectors are analyzed, with an average of 18 companies being analyzed and evaluated by about 13 analysts for each sector. This report contains the evaluation of industry experts primarily in the matter of voluntary and mandatory disclosures in three categories of documents:

(1) Published annual reports and other information requested;

(2) Quarterly reports and other information which is published but not requested;

(3) Other aspects of disclosure.

The final score is calculated using a weighted evaluation based on objective criteria of the analysts on the three elements above. This score will then be used as the assigned rating.

The indicator provided by the AIMR has been used in different studies as a measure of the level of disclosure (see, for example, Imhoff, 1992; Welker, 1995; Lang \& Lundholm, 1996; Sengupta, 1998; Healy, Hutton, \& Palepu, 1999; Bushee \& Noe, 2000; Botosan \& Plumlee, 2002; Gelb \& Zarowin, 2002; Byard \& Shaw, 2003), although currently it is no longer used as the organization in question discontinued its evaluation activities in 1997 after having carried out company evaluations for the fiscal year 1995.

The approach in question has also been used outside the American context through a ranking system provided by other organizations. An example is that of the Credit Lyonnais Securities Asia (CLSA), using a form of ranking to report on the perception of financial analysts on the analysis of the disclosure of the main aspects of governance of companies in emerging markets. This ranking is based on a questionnaire analyzed by CLSA using questions where the answers are of a dichotomous nature (yes/no) in order to reduce any subjectivity that the analysts may have in the evaluation (Krishnamurti, A. Sevic, \& Z. Sevic, 2005). 
Another example of using this approach for assessing disclosure is highlighted by research conducted by Coleman and Eccles (1997) who used the method of interviews to understand the opinion of 107 financial analysts and 102 investors on the adequacy of the disclosure methods on performance indicators, financial and otherwise, on the part of British companies.

Through the use of questionnaires and the analysis of available ratings, it is easier to assess the quality of disclosure, although this approach has many limitations (Fink, 1995; Gillham, 2000; Frazer \& Lawley, 2000).

In fact, some criticisms were raised on the use of this analysis method. Lang and Lundholm (1993) argued that the main weakness of this approach is the subjectivity of those responsible for assigning the rating, as they may have a different perspective from other users and express a judgment which does not represent the level of disclosure issued directly by the company.

Healy and Palepu (2001) pointed out that the criteria for the definition of ratings and the methods for including companies in the observation panel are not always clearly understood and as such, a score can be influenced by other factors.

Moreover, in addition to the criticisms mentioned above, it must be emphasized that in order to ensure a reasonable level of quality research, close attention must be paid to the structure of the questionnaires used; questionnaires which are unclear and/or contain insignificant questions can, in fact, disrupt the significance of the research taking place.

Another method for assessing the disclosure of a subjective nature is represented, according to some research (Lang, Lins, \& Miller, 2003; Irani \& Karamanou, 2003), by the number of financial analysts in support of the company, which would be in direct proportion to future provisional forecast indications consequently re-enforcing the information environment surrounding the company. In support of such information, Lang and Lundholm (1993) have found that companies which provide greater disclosure have a greater number of analysts at their disposal and a lower margin of error in determining profit forecasts. This explains the reason why greater disclosure can lead analysts to provide a more accurate analysis, as they have more supporting information available to them, which in turn increases the demand for their services (Healy \& Palepu, 2001).

\section{Objective Instruments for Measuring the Levels of Disclosure}

A second set of useful tools to detect the quality level of the disclosure is that of an objective nature, which is based on a direct analysis of original documents where the information is made available. The main objective instruments are those which are inherent to textual analysis, reporting on the frequency of disclosure and events, in addition to disclosure indexes which are widely used in research literature.

\section{Textual Analysis}

Textual analysis, also defined as content analysis, is based on the qualitative study of the vocabulary used in company documents to understand the content and the standardization of the same and it is a methodology that is spreading dramatically in studies of financial accounting (Beattie, 2005).

In particular, Krippendorff (1980, p. 98) defined content analysis as "a set of procedures to collect and organize information in a standardized format that allows the analyst to undertake inferential analysis on the characteristics and meaning of the recorded information”.

In order for the resulting analysis to be significant, it is necessary for the classification procedures to be reliable (different people encode a given text in the same way) and valid (variables generated by the classification procedure actually represent what the researcher wants to study) (Weber, 1985). 
In using the technique of content analysis, the total sum of information can be measured with reference to company categories, in order to count the amount of available information on a given topic, the number of words, and the number of sentences (see, for example, Hackston \& Milne, 1996).

Textual analysis can be carried out with reference to three main aspects: (1) thematic analysis; (2) analysis of syntax (or readability studies); and (3) linguistic analysis.

Thematic analysis focuses on determining the existence or frequency of certain types of words or key concepts related to a particular theme or topic. This type of analysis can "evolve" into a relational type of thematic analysis highlighting the relationships and connections between certain concepts present in a text. The analysis may be partial, examining only a section of a document or words, or complete, covering the entire document (Beattie, McInnes, \& Fearnley, 2004).

Syntax analysis focuses on the cognitive difficulty of reading text documents. In particular, studies relating to legibility are organized to quantify the cognitive difficulty of a text and typically use a "readability" formula like the Flesch index (an index based on the combination of the length of sentences and number of syllables of words). The score obtained is compared to external benchmarks in order to evaluate the level of difficulty and "fluidity" of the text being analyzed. These scores were applied to financial statements and annual reports to understand the level of readability. The issues raised in their adoption, however, are different: in the first instance, the approach analyses and evaluates a set of syllables, words, and sentences without considering the merits of the overall meaning of the concepts. Also, what can be easily understood and readable for a child may not be or otherwise be inappropriate for an adult reader of a balance sheet, without considering that the motivation and interests of the document in question may be different from user to user.

Finally, the most advanced category of content analysis is inherent linguistic analysis, which is based on the theory of communication-narrative developed by De Beaugrande and Dressler (1981) and the textual index developed by Roseberry (1995).

The first theory identifies seven basic principles that determine the effectiveness of the communication narrative based on the text and users. The Roseberry's (1995) index, however, on the basis of the study referred to above, identifies a criterion for the evaluation of the narrative using scores for each observation unit. Here, a score of 0 is assigned if the text characteristic is absent, 1 or 2 if it is present differentiating the two scores on the basis of the degree of existence of the same.

Based on the two abovementioned studies, Sydserff and Weetman (1999) developed a new method for the evaluation of the narrative aspects of the company annual report creating a new textual index aimed at evaluating certain attributes, such as current events, intertextuality, connection, connectivity, shifting information categories, specificity. After developing certain methods and rules for the classification of textual units, these were tested by researchers on the financial statements of 10 British companies listed on the FTSE-100. One of the advantages of the above methodology is that the narrative aspects of annual reporting are analyzed unit by unit allowing observers and researchers to capture the variability of textual reporting (Courtis, 1998).

From a practical point of view, content analysis consists of different phases (Carney, 1971). The first step is the selection of the companies to be studied and documentation to be analyzed, which in most cases is expressed in the annual report, as it was considered to be the best source of information for research of this type (Gray, Kouhy, \& Lavers, 1995). 
The second step is the choice of the unit to be measured to understand, in terms of quantity, the size of each information category found within the document being analyzed; different methods of measurement can be used such as part of the page, a phrase, a line, a word, paragraph, etc..

The next step focuses on the identification of information groups, in which the information being researched is reclassified using a pre-established theoretical reference framework (Carney, 1971) so that the reliability of the research is not affected by the subjectivity of the researcher.

The robustness of the research tool used is tested in the next step, in order to validate and confirm the validity of the same as well as the intrinsic procedural rules to be applied when making any adjustments, if required, in order to improve the analysis model.

The last step of content analysis is modeled on the coding of documents used in the analysis model previously studied. As pointed out by Krippendorff (1980), it requires that all researchers working on a specific research project, using the technique described above, classify the same information using the same methodology, to ensure that the encoding is effective. Once this has been done, the information can be transferred to electronic worksheets in preparation for subsequent statistical analysis (Kassarjian, 1977).

The technique of content analysis may also be conducted manually, with the aid of software or using both methods.

In traditional content analysis, the documents and keywords which are subject to analysis are researched manually without external aids. This methodology requires more resources in terms of time taken in the research employed, as well as human resources used (which may involve more than one individual in a single research, making it advisable to have a comparison in order to validate the data). This, therefore, represents a limitation in the use of this approach as it requires an increased use of resources and the process of collecting data is more difficult. This inevitably leads to the analysis of a smaller sample, as shown in previous studies (Jo \& Kim, 2007; Beattie \& Thomson, 2007).

As an alternative to the approach described above, or in conjunction with it, it is possible to take advantage of the research and textual coding through the use of specialist software.

This methodology has both advantages and disadvantages. Despite being an "economic" technique in terms of time, effort, and monetary resources and it is also has the advantage of being able to cover larger samples, it is not free from problems and/or issues. The main problems arise from the use of the correct text strings that allow for an accurate analysis, carefully ensuring the identification of all possible synonyms and different possible meanings that achieve a similar result to the main concept being researched. Furthermore, in research that uses the word count as a method of measurement, it is important that it too takes into account the possible words that are repeated in the notes to the balance sheet (or explain those which cannot be found or a determining parameter cannot be calculated for).

Therefore, in order to address the issues raised in automatic analysis, some authors resort to the use of both techniques (Hussainey, Schleicher, \& Walker, 2003; Beattie \& Thomson, 2007).

\section{Event Analysis}

A second approach used in international research to determine the level of information disclosed by the companies is the analysis of events; in particular the study of the frequency with which certain information is disclosed and analysis of the impact positive and negative news has on the level of disclosure. 
Some studies on voluntary disclosure are based on the frequency with which certain events are reported and disseminated to the public, with a view to understanding the quality level of the disclosure.

This approach is used less frequently in the international accounting literature, compared to other techniques such as content analysis and disclosure indexes.

Examples for the use of this methodology in determining the level of disclosure are provided by Lang and Lundholm (2000) who used an information measurement method based on all the published documents and which are available to third parties for each company. They used the frequency with which these documents are published and variation in these frequencies, the variation of which is representative of the level of disclosure.

Brown, Hillegeist, and Lo (2004) used proxy disclosure of the number of conference calls made by each company to measure the level of voluntary disclosure; another example of this approach can be seen in the research by Verrecchia (2004), which analyses the number of documents released by the companies in the three previous months before and after a public share offer.

Where disclosure is analyzed on the basis of the dissemination of good or bad news, this method is often used with reference to the expectation of estimated and actual profits. Empirical evidence shows that the disclosure of information, in the event of a positive performance scenario, is more timely and accurate. This is due to managers wanting to report to the market that the company is managing its affairs well, while "bad" news is disseminated often with qualitative expressions, relating to quarterly earnings announcements so as not to affect their own profile and avoid reputational damage related to delays in disclosing negative performance information (Skinner, 1994).

In this type of analysis, the difference between actual earnings and expected earnings as a proxy for the dissemination of "bad" news is used (in the event, the former is higher than the latter) or "good" news (in the event, actual profits reflect or exceed forecast expectations). This method has been used in different studies with different methodological adjustments (Clarkson, Kao, \& Richardson, 1994; Ali, Chen, \& Radhakrishnan, 2007).

\section{Disclosure Indexes}

The creation of special disclosure indexes is one of the most widely used techniques in accounting studies for the measurement of the level of disclosure of information. A disclosure index is a measure representing the level of information provided by the company, which can be considered voluntary and/or mandatory, calculated on the basis of specific elements observed based on one or more specific sources of information.

The first issue, therefore, in order to define the disclosure index which will represent the quality of disclosure, is found in the elements to be considered for creating the index. These can be mandatory items (for example, the information required by International Accounting Standards (IAS)/International Financial Reporting Standards (IFRS) international accounting practices for the purpose of implementing EU legislation, on the subject of evaluation criteria for balance sheets) or voluntary in nature (referring to the types of financial and non-financial information, the disclosure of which is not made compulsory by any regulatory body).

The first study on the disclosure of financial information to adopt the use of disclosure indexes was conducted by Cerf (1961) and was followed by numerous other studies.

This method for measuring the level of disclosure varies and is dependent on the composition of the information, even on the basis of the subject researched and the degree of importance attached to certain parts of the information by the researcher. With reference to this last observation, it is important to specify that in 
research focusing on disclosure, most researchers created ad-hoc indexes for the analysis they were undertaking (on the basis of the aspects of interest to the study), but it is not uncommon for cases where in order to measure the level of quality of disclosure using a score, the authors (e.g., Patel, Balic, \& Bwakira, 2002; Ali et al., 2007; Barron, Kile, \& O’Keefe, 1999; Salter, 1998; Hope, 2003a; 2003b) have relied on indexes created by external parties such as financial analysts or professional organizations (such as, for example, CIFAR "Centre for International Financial Analysis and Research"). The advantage of this approach, highlighted by Marston and Shrives (1991), is that it provides a greater possibility for comparison with studies previously conducted using the same indexes.

The ad-hoc disclosure indexes created by researchers, however, may consider different elements of disclosure (voluntary or mandatory), giving the same importance to the items considered or applying a weighted measure, attributing greater importance to certain aspects rather than others, for the purpose of creating a disclosure score. The two different approaches to the calculation of disclosure indexes are, therefore, referred to as "unweighted indexes" and "weighted indexes". For the purpose of defining and calculating disclosure indexes, it is necessary to follow certain steps.

The first step, to be carried out for the purpose of creating a disclosure index, is the selection of the information source to be referred to for the extraction and analysis of information content for the purposes of the study. Information retrieval can be carried out using different channels such as, for example, websites, company newsletter, press releases, meetings, etc..

One of the primary and most important sources of information is the annual report, regarded as the main document for financial and non-financial information (Knutson, 1992). The annual report is indeed the main document used by every company to interact directly with stakeholders (without the intervention of third parties) on a regular basis, providing a comprehensive level of accounting and other company information. For this reason, it is chosen by different researchers as a basic document for the collection of information (see, for example, Lee \& Tweedie, 1975; Anderson, 1981; Chang, Most, \& Brain, 1983; Firer \& Meth, 1986; Abdelsalam, 1990; Vergoossen, 1993; Hossain, Tan, \& Adams, 1994; Abu-Nassar \& Rutherford, 1995; Ho \& Wong, 2001).

After defining the study source, it is necessary to understand what elements will be the subject of analysis and therefore of interest, in the event of opting for ad-hoc construction of a score to be applied. Researchers who previously used this approach have chosen elements or items on the basis of aspects considered to be most relevant to the research itself, also making use of existing literature available on the subject (see Botosan, 1997). The use of discretionary selection of research elements is not exempt from criticism, especially as regards to comparisons with different studies and which becomes more difficult to implement using the above methodology (Marston \& Shrives, 1991).

Once the items have been selected and a sort of "check list" compiled, the former are measured quantifying their presence by means of a weighting. It is possible to use different scoring methodologies to define the final disclosure index, representing a proxy variable explaining the level of information provided by the company.

It is therefore possible to use a variety of approaches:

(1) Dichotomous: if the information is present, a score of 1 is assigned; if it is absent, a score of 0 is assigned; 
(2) Dichotomous and quantitative: if the information is present in qualitative and quantitative terms, a score of 2 is assigned; if the information is present only in qualitative terms, a score of 1 is assigned; and if it is absent, a score of 0 is assigned;

(3) Score range: a score is attributed to information detected ranging from a minimum score to a maximum score, based on certain parameters of the level of detail of information (for example, a score of 0-5 points on the basis of the level of element information disclosed).

Having done this, it is possible, or not to attribute a weighting to the score (the sum of the previous points) on the basis of the importance attributed by the researcher to certain aspects over others.

The approach using weighted disclosure indexes is affected by elements of subjectivity in determining the degree of relevance of the items which constitutes one of its main weaknesses (Ashton, 1974). Using a weighted disclosure index can reflect the needs of only one part of users and perception may also be affected by external factors (Firer \& Meth, 1986). Once the score has been attributed and possibly weighted, the disclosure index is used in different studies as a proxy for the quality of disclosure.

\section{Conclusions}

The information disclosed by companies is a constantly evolving subject, in part due to the increasing legislation that has an impact on the regulation of different types of information that companies share with stakeholders (whether voluntary or mandatory). This topic, in particular over the last decade, has been of great interest to accounting researchers. The quality of the information, however, is not always easily and immediately understood: different methods are used with a view to measuring it. For this reason, the discussion undertaken had as its aim to explain concisely the difficulties in measuring information with reference to all the primary relevant studies. The research work presented, therefore, considers the merits of the main methodologies used to measure the quality level of disclosure in international literature to date.

These tools, identified here in this work as being objective and subjective in nature, are categorized by researchers on the basis of specific requirements analyzed in various areas of research. These were personalized and modulated with reference to the context of application and research questions, providing a fundamental starting point for any researcher seeking to undertake studies in the vast, and "hot" topic of financial disclosure. This paper wants to contribute to existing accounting disclosure literature giving scholars and researchers a brief framework to simply understand the different methodologies used in accounting literature to assess the disclosure quality, providing examples of the application of the same in different research contexts.

\section{References}

Abdelsalam, M. (1990). The use of corporate financial reports by investors in Saudi Arabia. Advances in International Accounting, 3, 25-39.

Abu-Nassar, M., \& Rutherford, B. A. (1995). Preparers' attitudes to financial reporting in less developed countries with moderately sophisticated capital markets: The case of Jordan. The International Journal of Accounting, 30(2), 129-138.

Adrem, A. (1999). Essays on disclosure practices in Sweden: Causes and effects. Lund: Lund University Press.

Ali, A., Chen, T. Y., \& Radhakrishnan, S. (2007). Corporate disclosures by family firms. Journal of Accounting and Economics, 44(1-2), 238-286.

Anderson, R. (1981). The usefulness of accounting and other information disclosed in corporate annual reports to institutional investors in Australia. Accounting and Business Research, 11(44), 259-265.

Ashton, R. H. (1974). The predictive-ability criterion and user prediction models. The Accounting Review, 49(4), 719-732. 
Barron, O. E., Kile, C. O., \& O’Keefe, T. B. (1999). MD\&A quality as measured by the SEC and analysts' earnings forecasts. Contemporary Accounting Research, 16(1), 75-109.

Beattie, V. (2005). Moving the financial accounting research front forward: The UK contribution. British Accounting Review, 37(1), 85-114.

Beattie, V., \& Thomson, S. J. (2007). Lifting the lid on the use of content analysis to investigate intellectual capital disclosures. Accounting Forum, 31(2), 129-163.

Beattie, V., McInnes, W., \& Fearnley, S. (2004). A methodology for analysing and evaluating narratives in annual reports: A comprehensive descriptive profile and metrics for disclosure quality attributes. Accounting Forum, 28(3), 205-236.

Botosan, C. A. (1997). Disclosure level and the cost of equity capital. The Accounting Review, 72(3), 323-349.

Botosan, C. A., \& Plumlee, M. A. (2002). A re-examination of disclosure level and the expected cost of equity capital. Journal of Accounting Research, 40(1), 21-40.

Brown, S., Hillegeist, S. A., \& Lo, K. (2004). Conference calls and information asymmetry. Journal of Accounting and Economics, 37(3), 343-366.

Bushee, B. J., \& Noe, C. F. (2000). Corporate disclosure practices, institutional investors, and stock return volatility. Journal of Accounting Research, 38, 171-202.

Byard, D., \& Shaw, K. W. (2003). Corporate disclosure quality and properties of analysts' information environment. Journal of Accounting, Auditing and Finance, 18(3), 355-378.

Carney, T. F. (1971). Content analysis: A review essay. Historical Methods Newsletter, 4(2), 52-61.

Cerf, A. R. (1961). Corporate reporting and investment decisions. Berkeley: University of California Press.

Chang, L. S., Most, K. S., \& Brain, C. W. (1983). The utility of annual reports: An international study. Journal of International Business Studies, 14(1), 63-84.

Clarkson, P. M., Kao, J. L., \& Richardson, G. D. (1994). The voluntary inclusion of forecasts in the MD\&A section of annual reports. Contemporary Accounting Research, 11(1), 423-450.

Coleman, I., \& Eccles, R. G. (1997). Pursuing value: Reporting gaps in the United Kingdom. PricewaterhouseCoopers.

Cormier, D., Magnan, M., \& Van Velthoven, B. (2005). Environmental disclosure quality in large German companies: Economic incentives, public pressures or institutional conditions? European Accounting Review, 14(1), 3-39.

Courtis, J. K. (1998). Annual report readability variability: Tests of the obfuscation hypothesis. Accounting, Auditing and Accountability Journal, 11(4), 459-471.

De Beaugrande, R., \& Dressler, W. (1981). Introduction to text linguistics. Harlow: Longman.

Fink, A. G. (1995). How to sample in surveys (Vol. 6: The survey kit). Thousand Oaks, CA: Sage Publications.

Firer, C., \& Meth, G. (1986). Information disclosure in annual reports in South Africa. Omega, 14(5), 373-382.

Frazer, L., \& Lawley, M. (2000). Questionnaire design and administration: A practical guide. Brisbane, Australia: John Wiley \& Sons.

Gelb, D. S., \& Zarowin, P. (2002). Corporate disclosure policy and the informativeness of stock prices. Review of Accounting Studies, 7(1), 33-52.

Gillham, B. (2000). Developing a questionnaire (Real world research). London: Continnuum.

Gray, R., Kouhy, R., \& Lavers, S. (1995). Corporate social and environmental reporting: A review of the literature and a longitudinal study of UK disclosure. Accounting, Auditing and Accountability Journal, 8(2), 47-77.

Hackston, D., \& Milne, M. J. (1996). Some determinants of social and environmental disclosures in New Zealand companies. Accounting, Auditing and Accountability Journal, 9(1), 77-108.

Hassan, O., \& Marston, C. (2010). Disclosure measurement in the empirical accounting literature - A review article. Accountancy Discussion Papers, No. 1004, Accountancy Research Group, Heriot Watt University.

Healy, P. M., \& Palepu, K. G. (2001). Information asymmetry, corporate disclosure, and the capital markets: A review of the empirical disclosure literature. Journal of Accounting and Economics, 31(1-3), 405-440.

Healy, P. M., Hutton, A. P., \& Palepu, K. G. (1999). Stock performance and intermediation changes surrounding sustained increases in disclosure. Contemporary Accounting Research, 16(3), 485-520.

Ho, S. M., \& Wong, K. S. (2001). A study of corporate disclosure practice and effectiveness in Hong Kong. Journal of International Financial Management and Accounting, 12(1), 75-102.

Hope, O. K. (2003a). Disclosure practices, enforcement of accounting standards, and analysts' forecast accuracy: An international study. Journal of Accounting Research, 41(2), 235-272.

Hope, O. K. (2003b). Accounting policy disclosures and analysts’ forecasts. Contemporary Accounting Research, 20(2), $295-321$. 
Hossain, M., Tan, L. M., \& Adams, M. (1994). Voluntary disclosure in an emerging capital market: Some empirical evidence from companies listed on the Kuala Lumpur Stock Exchange. The International Journal of Accounting, 29(4), 334-351.

Hussainey, K., Schleicher, T., \& Walker, M. (2003). Undertaking large-scale disclosure studies when AIMR-FAF ratings are not available: The case of prices leading earnings. Accounting and Business Research, 33(4), 275-294.

Imhoff, E. A. (1992). The relation between perceived accounting quality and economic characteristics of the firm. Journal of Accounting and Public Policy, 11(2), 97-118.

Irani, A. J., \& Karamanou, I. (2003). Regulation fair disclosure, analyst following, and analyst forecast dispersion. Accounting Horizons, 17(1), 15-29.

Jo, H., \& Kim, Y. (2007). Disclosure frequency and earnings management. Journal of Financial Economics, 84(2), 561-590.

Kassarjian, H. H. (1977). Content analysis in consumer research. Journal of Consumer Research, 4(1), 8-18.

Knutson, P. (1992). Financial reporting in the 1990s and beyond: A position paper of the association for investment management and research. Working Paper, University of Pennsylvania.

Krippendorff, K. H. (1980). Content analysis: An introduction to its methodology. Newbury Park, CA: Sage Publications.

Krishnamurti, C., Sevic, A., \& Sevic, Z. (2005). Voluntary disclosure, transparency, and market quality: Evidence from emerging market ADRs. Journal of Multinational Financial Management, 15(4-5), 435-454.

Lang, M. H., \& Lundholm, R. J. (1993). Cross-sectional determinants of analyst ratings of corporate disclosures. Journal of Accounting Research, 31(2), 246-271.

Lang, M. H., \& Lundholm, R. J. (1996). Corporate disclosure policy and analyst behavior. The Accounting Review, 71(4), 467-492.

Lang, M. H., \& Lundholm, R. J. (2000). Voluntary disclosure and equity offerings: Reducing information asymmetry or hyping the stock. Contemporary Accounting Research, 17(4), 623-662.

Lang, M. H., Lins, K. V., \& Miller, D. P. (2003). ADRs, analysts, and accuracy: Does cross listing in the United States improve a firm's information environment and increase market value? Journal of Accounting Research, 41(2), 317-345.

Lee, T. A., \& Tweedie, D. P. (1975). Accounting information: An investigation of private shareholder usage. Accounting and Business Research, 5(20), 280-291.

Marston, C. L., \& Shrives, P. J. (1991). The use of disclosure indices in accounting research: A review article. British Accounting Review, 23(3), 195-210.

Meek, G. K., Roberts, C. B., \& Gray, S. J. (1995). Factors influencing voluntary annual report disclosures by U.S., U.K. and Continental European multinational corporations. Journal of International Business Studies, 26(3), 555-572.

Patel, S. A., Balic, A., \& Bwakira, L. (2002). Measuring transparency and disclosure at firm-level in emerging markets. Emerging Markets Review, 3(4), 325-337.

Roseberry, R. L. (1995). A texture index: Measuring texture in discourse. International Journal of Applied Linguistics, 5(2), 205-223.

Salter, S. B. (1998). Corporate financial disclosure in emerging markets: Does economic development matter? The International Journal of Accounting, 33(2), 211-234.

Sengupta, P. (1998). Corporate disclosure quality and the cost of debt. The Accounting Review, 73(4), 459-474.

Skinner, D. J. (1994). Why firms voluntarily disclose bad news? Journal of Accounting Research, 32(1), 38-60.

Sydserff, R., \& Weetman, P. (1999). A texture index for evaluating accounting narratives: An alternative to readability formulas. Accounting, Auditing and Accountability Journal, 12(4), 459-488.

Vergoossen, R. G. A. (1993). The use and perceived importance of annual reports by investment analysts in the Netherlands. European Accounting Review, 2(2), 219-244.

Verrecchia, R. E. (2004). Policy implications from the theory-based literature on disclosure. In The economics and politics of accounting (pp. 149-163). Oxford Press.

Weber, R. P. (1985). Basic content analysis. Beverly Hills, CA: Sage Publications.

Welker, M. (1995). Disclosure policy, information asymmetry, and liquidity in equity markets. Contemporary Accounting Research, 11(2), 801-827. 